\title{
Overtime Addiction
}

Eric C. Jackson, Penn State - Erie, Behrend College

Peg Thoms, Penn State - Erie, Behrend College

\begin{abstract}
Overtime is common in business. Companies use it to respond to excess demand without increasing the number of employees. Employees do it as a means of increasing their income. It contributes to communities by increasing disposable income. However, it can become an addiction as companies, employees and communities come to depend on it as a part of their subsistence instead of a temporary benefit. This paper explains this problem and offers specific suggestions for managers who want to cure or prevent overtime addiction.
\end{abstract}

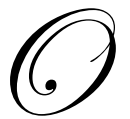

vertime is a double edged sword for both employees and organizations. Employees who work extensive overtime and employers who rely on overtime have become addicted to it (Robinson, 1989)because, like all addictions, it feels good and provides an escape from life. Workers might be addicted to the enjoyment of their profession and the work that they do, the additional income, the organizational prestige associated with working long hours, and the escape from boring or difficult personal situations. Managers might be addicted to the use of overtime in order to spend more time at the work they enjoy and/or the business which they own, to deal with unplanned surges in work or emergencies, to avoid long-term planning, and/or to manage impressions of the importance of them and their departments. Overtime Addiction (OA), like other addictions, also has severe consequences over time in addition to its benefits. People have less time to spend with their families and friends, feel increased stress, and develop personal problems including increased financial obligations, health problems, and workaholism (Harpaz and Snir, 2003). This may be especially true in a corporate culture that values working long hours (Beder, 2000, Friedman and Lobel, 2003, Schaef and Fassel, 1998). For managers, overtime substantially raises the costs of doing business and often leads to a loss of management control. Overtime Addiction can also affect communities by increasing the need for community resources necessary to deal with family problems and the loss of employment opportunities. We suggest that overtime is an addiction which effective managers can cure and avoid. In this paper, we outline how overtime, as an entity, develops and persists, the negative consequences often associated with overtime, and how managers can prevent overtime from becoming an addiction within their organizations.

Non-exempt employees love overtime because they make at least $50 \%$ more per hour and that additional pay can help them make major purchases, take better care of their families, and help their companies (DeGraaf, et al., 2001). Many such workers look for overtime in order to make additional money. Many also work overtime in order to affect their retirement formula which provides a long-term reward for working extra hours now. Exempt employees, who do not earn overtime pay (due to laws regulating overtime compensation), may also love overtime because it gives them a visible and measurable way to prove that they are promotable. They are also more likely to be professionals who chose to work in their fields and may love the work that they do. In addition, many people, especially workaholics, use work as an escape from difficult home situations (Hochschild, 1997, Hodson, 2004). Of course, these home situations often get worse because of extensive overtime. Work is a "good" excuse that few spouses, children and other family members can counter.

Managers in organizations love overtime because it is a quick and easy way to respond to emergency situations, seasonal surges in work, and other unexpected work loads without doing additional hiring (Hendrick, 2000). Hiring new employees creates long-term obligations like health insurance and other costly benefits, including, ironically, sick leave and vacation time. These organizations can also avoid the forecasting and planning functions, which are difficult, expensive, time- consuming, and complex processes, by using overtime. 
Like many other substances and situations that people love to hate, overtime has become a mutual addiction. Blue collar workers who make over $\$ 100,000$ per year with overtime spend like people who earn $\$ 100,000$. In a relatively short period of time, they find that the "extra money" has become an important and integral part of their family budget. For example, instead of buying homes in the range of what they can afford on their "regular" pay, they buy homes in the range of what those making $\$ 100,000$ can afford. Like other addictions, the financial and emotional impact on the workers and their families can be devastating (Elster, 1999, Fraser, 2001).

Managers in organizations hate overtime because it is expensive and makes it harder to keep labor costs within budget. According to the Bureau of Labor statistics the seasonally adjusted number of overtime hours manufacturing companies used per week in 2004 was 4,500. This data does not include overtime in other industries. (Statistics, 2007) A more specific example is that in 2005, four production workers made over $\$ 200,000$ with their overtime pay in one Fortune 500 manufacturing organization in the northeast. An additional 54 production workers made over $\$ 100,000$ per year by their overtime pay. Considering the scope of the work done by these workers, this level of pay was grossly out of line. Since the overtime rate of two times the regular hourly rate of $\$ 27$ per hour was mandated by the union contract, the managers in this firm cannot change the terms unless they change the contract which would be virtually impossible.

Organizations that utilize overtime extensively are likely to see increased costs and lower profit margins. Hendrick (2000) found that during the growth period that ended in 1998 overtime had increased 67\% while total employment remained lower then it had been in 1989, the point he marks as the depth of the recession that ended in 1991. Interestingly, the assumption that using overtime is more productive or cost effective than creating jobs has not been clearly established. Barkume (2007), in a study for the U.S. Bureau of Labor Statistics, concluded that he could not rule out the possibility that workers with overtime are actually less productive. There is often little accountability for the actual work done during the extra hours when others have left the office (Ciulla, 2000). Based on our own previous work experiences (as hourly workers, professionals, and managers) and interviews with others, overtime is almost always more "fun" because managers, if present at all, are grateful that workers are there and do not monitor the work quality and quantity closely; the employees are more apt to talk and joke more; and, management often provides perks like pizza, beverages, and sandwiches. Most readers can probably tell tales of after-hours activities of managers and others which have nothing to do with work including card games, long coffee breaks, and romantic relationships. Since many workers view overtime as doing the company a favor, there is a reduced feeling of obligation toward the employer and an increased feeling that the company owes them in the future. Combine this attitude with a need for money or escape, and you may be creating an insidious psychological problem or addiction.

In addition to the costs and the possibility of decreased productivity, there are other issues. There may be a loss of management control as addicted workers manipulate production rates in order to obtain overtime. Managers on salary can actually earn less than nonexempt subordinates and often become dissatisfied with their pay. Previous research has found that workaholism has negative consequences for organizations including higher absenteeism (Porter, 1996).

In addition to the problems for the workers and the employers, communities also suffer. This is one side of the problem of overtime addiction which is often ignored. Potential employers may not locate in an area known for high labor costs, divorce rates. Other family problems can increase leading to more households with family service needs. Companies may relocate because they cannot renegotiate union contracts, and local governments must deal with the consequences of the problems created by overtime addiction. And, of course, these issues must be addressed with reduced tax revenue and volunteer donations because of the increasingly poor economic conditions in the community.

Let's take this problem apart and look at each aspect of overtime addiction. To solve the problem, we must understand how it fits together. 


\section{CAUSES OF OVERTIME}

Managers have control over the causes of overtime and the conditions that exist during overtime. Overtime addiction is preventable if managers control the causes and change the conditions during overtime which make it addictive. This is not a complicated process and it could have dramatic and positive effects on the employees, employers, and their communities.

The causes of overtime include:

1. Poor aggregate planning for 6-12 months - managers can eliminate overtime by carefully planning for both the short and long term.

2. Short-term or long-term labor shortage - managers can anticipate labor shortages by monitoring the environment, following local economic patterns, tracking the time it takes to fill positions, and the use of attitude surveys.

3. A Hiring freeze - any hiring freeze can lead to the need for overtime.

4. New product rollout - managers who attempt to roll out new products and services without hiring the personnel necessary to staff the new product will create overtime, as well as sabotage its potential success.

5. Seasonal business surges.

6. Lean Manufacturing - A lean manufacturing environment, one that eliminates waste, should dampen the demand for overtime as a source of waste. However, there is evidence that lean manufacturing often increases the demand for overtime. While working for Toyota, a firm often held up as the optimal example of lean, Mehri (2006), observed that the Toyota system frequently led to excessive overtime. In some cases, the system created shifts of over 30 hours at a time for employees. Furthermore, since inventory, production capacities, and employment levels have been reduced to a minimum they cannot be used to mitigate surges in demand.

7. Supply Chain Management - Mehri (2006) also observed that lean did not reduce or remove the waste of overtime in the supply chain. Rather, he saw that the overtime was shifted upstream from large supply chain members to smaller supply chain members that did not have sufficient supplier power to resist the demands of their large buyer. This forced them to institute high levels of overtime. The end result was that the costs were absorbed by small firms with fewer slack resources than firms such as Toyota.

8. Overtime addiction - the consequences of overtime addiction (see later in this article) become causes creating overtime later in the cycle. For example, workers may slow down their work in order to make overtime available. As one worker put it after overtime hours were cut one week, "We are being penalized because we worked efficiently." Overtime had become an entitlement to him.

\section{CONDITIONS THAT EXIST DURING OVERTIME}

The conditions that exist during overtime determine whether overtime becomes an addiction. For example consider the following conditions that often occur during overtime:

1. Mandatory/voluntary - if employees are allowed to volunteer for overtime, those who volunteer are more apt to become addicted.

2. Number of hours/days/weeks - the greater the number of hours worked per day, days per week, and weeks per year, the greater the likelihood that addiction will occur. Overtime becomes an addiction becomes an entitlement. When it is cut, both the workers and the managers may be upset.

3. Length of time - the longer that overtime lasts (i.e., one summer versus one year), the greater the likelihood of addiction.

4. Elasticity of need - the more money employees make, the more they need. Specifically, we are suggesting that our basic needs grow as more money is pumped into our family budgets. Take for example the first paycheck with overtime in it. This extra money feels good. The worker and the family can do or buy something special that week. However, by the time the fourth check which includes overtime pay arrives, the money might have been built into the family's lifestyle and budget. 
a. Durability of money - money is not durable. Unless the employee is saving the extra income, he/she is likely to commit to new debt (car payment, mortgage, etc.) and the more money he/she will need after the organization's overtime needs have been met.

b. Inflation - increases in the cost of living may encourage employees to volunteer for overtime instead of alternatives like adjusting spending, working harder to increase piecework pay, or trying to earn a promotion.

c. Overtime pay rate - the more money one needs, the less satisfied one becomes with $1 \frac{1}{2}$ times the hourly rate. This pressures unions to negotiate higher rates of overtime pay. Unions can only do this in poorly managed environments where overtime addiction develops. Once overtime is paid at 2 or more times hourly rates, addiction will increase exponentially.

5. Technological connectedness - due to the use of cell phones and other handheld devices, employees may be working even when they are not present. This $24 / 7$ connectedness means that overtime goes on continuously and becomes more addictive. It is common for exempt professionals to talk about their "relationship" with their Blackberry. Since professionals are typically exempt employees, they are not addicted to overtime pay, but rather to the connectedness or the implied promise of other rewards, like promotions, that go to the hardest (i.e. always available) workers.

\section{CONSEQUENCES OF OVERTIME ADDICTION}

Overtime Addiction has a number of serious consequences for organizations. These consequences impact individuals, organizations, and communities. They include:

1. Employee dependency:

a. Financially over-extended individuals dependent on overtime pay to meet their fixed expenses like mortgage payments. It is not unusual to hear people say that they worked overtime to save for the down payment on a house, but they worked so much that they could afford a bigger home with the down payment they saved. And, then, they had to work overtime to make the payments on the bigger home. It appears that some spouses who are "ignored" by the worker with long hours make more demands on their spouse for material goods. This doesn't just happen to lawyers and doctors, but also factory workers and police officers who work very long days and weekends.

b. Workaholism leads to feelings of comfort only when working. It also develops a belief that one must work as much as possible. (Is there supposed to be a connection here? If not, you need a third sentence that is a disclaimer that the two aren't mutually inter-related.)

c. Escape from problems (in particular, family problems) created by overtime encourages employees to work more overtime. This used to be considered a "male" issue, but new studies show that women are now using work to escape from difficult home situations which escalate the more one works (Hochschild, 1997).

2. Organizational dependency

a. Increased business costs due to overtime rates. Nonexempt employees must be paid at a rate $1 \frac{1}{2}$ times their hourly wage. Sometimes, labor unions will negotiate higher rates of pay for overtime which may be twice the hourly rate.

b. Loss of management control when employees deliberately slow down work in order to get more overtime hours. There are numerous examples of work slowdowns by employees in order to obtain overtime. As all managers know, this does not mean, however, that employees will not complain about the overtime. Overtime is a Catch 22 in that, employees want and hate it simultaneously. (You've said nothing about the "hate" issue. Perhaps a word here. Things are not transparently observable or deducible to the reader.) Employers cannot win either way -a common characteristic of all addictions.

c. Increased costs of doing business lead to higher prices compared to competitors that have better controls on the causes and conditions of overtime. 
d. Pay dissatisfaction of supervisors \& managers who work very long hours during overtime periods but are exempt from overtime provisions and can make less than their subordinates.

e. Union problems because both too much and not enough overtime cause complaints and unions have a significant incentive to resist hiring more employees or outsourcing the work. The more overtime an organization needs, the lower its power with its union.

f. Inability to complete work during 40-hour time periods or shifts. This can occur not just as a result of deliberate slowdowns, but also because workers are tired and stressed due to the overtime.

g. Aggregate Planning should decrease overtime, but one of the consequences of overtime addiction is that planning cannot be done. In essence, the system of addiction takes over and makes planning difficult and/or unlikely to be implemented. Everyone is too busy to plan.

h. Slower work rates and quality during overtime can result. Those who have already worked eight hours will not be as productive during the extra hours. In addition, those workers who volunteer for overtime may not be the workers who have the expertise on specific machines or types of work that must be done during the overtime. This means that inexperienced workers are doing the work and both quantity and quality problems are likely.

3. Community issues

a. Exodus of employers who want to avoid strong union environments and regional norms regarding overtime provisions. In addition, some businesses will be forced to close.

b. Increases in the use of community agencies due to the problems related to workaholism and fewer people to provide services. For example, we would expect to find increased divorce rates, children with less supervision because parents are working and reduced volunteerism because citizens are working. For example, in many small communities dependent on volunteer fire departments, finding volunteers is already a problem.

c. Difficulty hiring or keeping good workers by small companies in the area because they cannot afford the same pay structures and overtime rates as the larger organizations.

\section{CURING OVERTIME ADDICTION}

A number of fairly simple and straight forward management strategies could change the cycle of Overtime Addiction. While most of these ideas make sense anyway, few managers realize their connection to overtime.

1. Aggregate Planning could and should have a negative impact on overtime once adjustments to the plan have been made and implemented. This damping affect is not instantaneous but should begin to have an impact after a six to twelve month time period. Planning includes the forecasting of labor needs. There are a number of forecasting techniques and software tools which can reduce the unexpected demand for workers.

2. Control of labor needs through careful planning and hiring. Companies which consistently use overtime do not have adequate staff to do the work. Although workers and unions may support low staffing levels when an overtime addiction exists, companies must readjust their staffing plans accordingly.

3. Limit the hours and length of time that overtime is used. The organization should have a standing policy that limits the amount of overtime that can be used each month. Senior managers must hold the line on those maximums. As the maximum level is approached and after reviewing patterns over the entire year, the Human Resources Department should begin planning for hiring.

4. Many organizations allow workers to volunteer for overtime. This is not a good strategy. Certain employees will begin to develop an addiction which will force them to volunteer or believe that they "deserve" the overtime when it is available because they volunteered in the past. Instead, let all employees know that overtime is necessary on occasion and that all will be called upon to work. Keep the number of hours short and try to accommodate special scheduling needs whenever possible.

5. Do not exceed overtime rates mandated by law. For many employers, it is too late to renegotiate contracts which may pay overtime rates over the legally mandated amount of $1 \frac{1 / 2}{2}$ times pay. If it isn't too late, organizations should never agree to more than the $1 \frac{1}{2}$ multiplier unless the overtime is going to be worked 
on a holiday. If an employer is so desperate that it is willing to pay double for overtime, it should hire more workers instead. In the long run, the cost is less.

6. Typically, organizations pay overtime by including it in an employee's regular bi-weekly paycheck. It would help everyone if overtime was paid in a lump sum. This way, employees and managers are reminded that this is not part of either personal or organizational monthly budgets. A separate check also reinforces the percentage of the "extra money" that goes to taxes, making overtime less attractive. It also makes tracking both the specific rewards and costs of overtime easier. When an employee and an organization incorporate the income and the costs into a regular paycheck, it is more likely that they will become addicted because the overtime does not seem "abnormal".

7. Use temporary workers and part-timers during seasonal surges and new product rollouts. Many organizations have started using temporary workers as a strategy to avoid overtime and to test potential new hires before employing them. Instead of overtime, temporary workers would make more sense than overtime for regular full-time employees. As the labor market shifts, however, this may not be possible for long. If the labor needs can be anticipated, it might be possible to establish long-term relationships with providers of temporary employees who represent workers. Some people enjoy rotating among different jobs and organizations because the work does not become tedious and boring over the long-run.

8. Managers with predictable seasonal surges in business may be able to offer discounts to customers to purchase goods and services throughout the year to even out production and avoid overtime

9. Monitor and discourage overtime by salaried exempt employees except during special situations and ensure the temporary nature of the overtime. It is common for organizations to "take advantage" of (or at least not worry about) salaried employees because the company does not have to pay overtime. There is a sense that there is no cost, but there is, in truth, a very high cost. Burnt out workaholics do not make the best employees. In management positions, they are very likely to encourage overtime by nonexempt employees. That way, they do not have to work alone, and they look and feel busier when they have a staff supporting their long hours. Overtime addiction is just as dangerous when it does not cost more in pay.

10. Increase hiring selectivity. One of the major causes of overtime is poor or slow work performance. Another cause is bad management. By improving the quality of the workforce, in general, both causes can be addressed. Paying well, treating employees fairly, and having organized and competent management can reduce overtime substantially.

11. Reconsider 24/7 technological connectedness during time away from work. Just because managers can stay connected doesn't mean that they should. Overtime is overtime, even when it isn't on the clock. Research has found that the old cliché is true - work expands to fill the time allowed. Calling and emailing employees after regular work hours is overtime. It can lead to the same problems as extra hours on-site.

12. Consider group incentive pay related to cost savings and profitability. Research suggests that group incentives like gain-sharing and profit-sharing effectively cut costs like overtime pay and other waste. Well-managed organizations use these strategies for all employees at every level.

13. Pay fair wages and benefits which cover decent living costs. If employees are underpaid or must buy their own health insurance, they are more likely to aggressively pursue overtime. They are also more likely to moonlight which has the same addictive effects as working overtime.

14. Generally speaking, men and women are still different in their attitudes regarding overtime. Women prefer compensatory time to overtime pay (Strassel, 2006). This is probably due to the "second shift" which still falls upon women in our culture (Hochschild, 2003). The law still requires pay for non-exempt employees (attempts to change the laws have been unsuccessful so far), but providing compensatory time and requiring exempt employees to use it within specific guidelines, can help organizations overcome Overtime Addiction and retain quality workers. This is a trend among many organizations (Kuhn and Lozano, 2006).

15. As the labor shortage begins to develop in the United States, there will be higher demands on employees to work long hours. However, the organizations which survive and are able to continue to hire the best employees will unquestionably be those who take the best care of the ones that they have.

16. Create a program of reverse overtime. In other words, implement strategies which reward workers for finishing work in less than eight hours. There are many piecework compensation methods which serve this purpose, other approaches which could be used with exempt workers to provide rewards for more efficient work. 
17. Close work buildings so that working extra hours is not possible. Research shows that workers fill the time available. Limiting the available time by closing the facility could actually increase productivity as well as save money.

The key to preventing Overtime Addiction is good management, good planning, the careful monitoring of the use of overtime with non-exempt employees and long hours for exempt employees, and changing traditional corporate cultures which value face time over productivity. Effective leaders never let Overtime Addiction develop. If a manager inherits this addiction, he will slowly have to wean managers and workers off this drug. If you are currently facing Overtime Addiction, the cure will be very difficult but, as with any other addiction, will only get harder the longer it continues.

\section{REFERENCES}

1. Barkume, A. J., 2007. Some New Evidence on Overtime Use, Total Job Compensation, and Wage rates. In: Conditions, U. S. B. o. L. S. O. o. C. a. W., (Ed., Working Paper 402.)

2. Beder, S., 2000. Selling the work ethic. Scribe Publications, Carlton North, Victoria, Australia.

3. Ciulla, J. B., 2000. The wroking life: The promise and betrayal of moder wrok. Times Books/Random House, New York, NY.

4. DeGraaf, J., Wann, D., and Naylor, T. H., 2001. Affluenza: The all-consuming epidemic. Berrett-Koehler, San Francisco, CA.

5. Elster, J., 1999. Emotion and addiction: Neuroboilogy, culture, and choice. In: Elster, J., (Ed., Addictions Entries and exits. Russell Sage Foundation, New York, NY

6. Fraser, J. A., 2001. White-collar sweatshop: The deterioration of work and its rewards in corporate America. Norton \& Company, New York, NY.

7. Friedman, S. D., and Lobel, S., 2003. The happy workaholic: A role model for employees. Academy of Management Executive 17, 87-98.

8. Harpaz, I., and Snir, R., 2003. Workaholism: Its definition and Nature. Human Relations 56, $297-319$.

9. Hendrick, R. L., 2000. Analyzing the recent upward surge in overtime hours. National Labor Review February 2000.

10. Hochschild, A. R., 1997. The time bind: When work becomes home and home becomes work. Owl Books, New York, NY.

11. Hochschild, A. R., 2003. The second shift. The Penguin Group, New York, NY.

12. Hodson, R., 2004. Work Lide and social fulfillment: Does social affiliation at work reflect a carrot or a stick? Social Science Quarterly 85, 221-239.

13. Kuhn, P., and Lozano, F., 2006. The expanding workweek? Understanding trends in long work hours among U.S. men, 1979-2004. NBER Wroking Paper No. 11895.

14. Mehri, D., 2006. The darker side of lean: An insider's perspective on the realities of the Toyota Production System. Academy of Management Perspectives 20, 21-42.

15. Porter, G., 1996. Organizational impact of workaholism: Suggestions for researching the negative outcomes of excessive work. Journal of Occupational Health Psychology 1, 1-15.

16. Robinson, B. E., 1989. Work addiction. Health Communications, Deerfield Beach, FL.

17. Schaef, A. W., and Fassel, D., 1998. The addictive organization. Harper \& Row, San Francisco, CA.

18. Statistics, B. o. L., 2007. U.S. Department of Labor Bureau of Labor Statistics.

19. Strassel, K., 2006. Make my mother's day. The Wall Street Journal. 
NOTES 